\title{
The Translational Eco-environment of Pinteresque Language and the Construction of Audience Acceptance Space*
}

\author{
Sainan Li \\ Faculty of Foreign Language, Huaiyin Institute of Technology, Huaian, China \\ $\mathrm{Zi} \mathrm{Li}$ \\ Faculty of Foreign Language, Huaiyin Institute of Technology, Huaian, China
}

\begin{abstract}
This study applied eco-translatology to drama translation. It's showed that the key to successful drama translation is how to properly deal with various elements in the ecological environment of drama translation, and always take the interpretation and acceptance of the actors and the audiences in the target language as an important criterion. Therefore, under the perspective of eco-translatology, three features of the translation of Pinteresque language, namely the life-oriented, action-directed and character-targeted features, need to be realized to complete the construction of audience's acceptance space, so that more audiences in the Chinese mainland can enjoy and fully appreciate the beauty of Pinter's outstanding drama.
\end{abstract}

Index Terms - eco-translatology, Pinteresque language, life-oriented, action-directed, character-targeted

\section{INTRODUCTION}

Harold Pinter was a Nobel Prize-winning British playwright, one of the most influential modern British dramatists, his writing career spanned more than 50 years. His plays are noted for their use of understatement, small talk, reticence---and even silence---to convey the substance of a character's thought, which often lies several layers beneath, and contradicts, his speech. He occupies a position as a modern classic which is illustrated by his name entering the language as an adjective used to describe a particular atmosphere and environment in drama: "Pinteresque". The Swedish Academy defines characteristics of the Pinteresque as: Pinter restored theatre to its basic elements: an enclosed space and unpredictable dialogue, where people are at the mercy of each other and pretence crumbles.

\section{Pinteresque Language AND ECO-TRAnSlatology}

The traditional drama often revises the stammering, pause, repeating, contradiction and errors of everyday language into a smooth and flawless language like ironed. In comparison, Pinter's drama leaves the impression as: wait a minute, let's look at the language itself. He is free from the trap of linguistic efficiency, which is to express as much meaning as possible in as few words as possible (Silverstein, 1993). He tried to bring his dramatic language close to the language of real life. Sometimes he deliberately repeats and it's verbose, which is obviously not economical considering the linguistic efficiency. But this kind of repetition and hesitation can often more skillfully explain the situation and mentality of the characters at the time (Taylor, 1969). This "Pinteresque" language has attracted wide attention in academic world. In the opinion of Fang Bolin, to a large extent, Pinter's plays can be said to be linguistic plays (Fang, 1996). John Russell Brown thought "Pinter promoted the expressiveness of drama language", and language is vital for Pinter drama, because "the interactions between the poles as the trust and fear for language, what language can achieve and fail to achieve becomes a gripping force in Pinter's dramatic dialogue, like blood and nerve of all his works" (Brown, 1984). Esslin Martin also showed that Pinter's use of language and non-language is perhaps his most important contribution to contemporary drama (Essin, 1970). A.Sykes pointed out that surely the most serious aspect of the Pinter play is its language (Sykes, 1970). While in China, Pinter's dramas have been performed several times. However, few scholars have ever discussed the performance of Pinteresque language in theater, which involves two aspects: the translation of Pinteresque language and the audience's acceptance space.

Considering the translation of Pinteresque language, there is a translation theory named eco-translatology proposed by domestic scholar Hu Gengshen (2008), according to whom eco-translatology can be understood as an ecological

\footnotetext{
* This paper is the periodical achievement of the project of A Study of Pinter's Plays From the Perspective of Space Criticism supported by Philosophy and Social Science Foundation of Jiangsu Provincial Department of Education with item number 2017SJB1630 and the project of Construction of the Ecological Translation Environment of Internet Popular Words supported by Social science Foundation of Jiangsu Province with item number 15YYD001. 本文系江苏省教育厅高校哲学社会科学基金课题（批准号: 2017SJB1630): 空间批评视域下的品特戏剧研究及江 苏省社会科学基金项目（批准号：15YYD001）：网络流行语的翻译生态环境构建研究的阶段性成果。
} 
approach to translation studies or translation studies from an ecological perspective, emphasizing the translational eco-environment in the process of translation and translators' adaptive selection, proposing the translational concept of "translator-centered" and focusing on translation process, translation principles, translation methods and translation evaluation criteria. The "translational eco-environment" in eco-translatology refers to the world presented by source language and target language, which is an entirety of interconnection and interaction between the language, communication, culture, society and the author, reader, entrusting party. Drama is also a kind of literary work, which requires readers' appreciation to be of vitality. The readers of drama translation include not only the readers of the text, but also the audiences of the performance of target language, as well as the directors and actors who use translational text of the drama. The key to successful drama translation is how to properly deal with various elements in the ecological environment of drama translation, and always take the interpretation and acceptance of the actors and the audiences in the target language as an important criterion, so that drama translation can better adapt to the translation ecological environment and construct the audience's acceptance space. The specific implementation method includes three aspects: under the guidance of ecological translation, to realize the life-oriented, action-directed and character-targeted features of the translation of Pinteresque language with specific translation skills to complete the construction of audience's acceptance space.

\section{The Translational Eco-EnVironment of Pinteresque Language And the Construction OF AudiEnCE} ACCEPTANCE SPACE

\section{A. To realize the Life-oriented Feature of the Translation of Pinteresque Language}

Drama is a living system, which contains all kinds of cultural elements: language environment, story background, social customs, etc., which widely involves many aspects such as linguistics, psychology and social culturology. At different times in different places, its appearance, meaning and value are different for different groups of people. It is possible to see certain language information which is plain and straightforward for one receiving group may not be easy to understand for another receiving group.

Drama translation, like many other types of literary translation, is to some extent, a process of intercultural communication, for which the most difficult is the difference between linguistic and social culture. The unspoken and metaphorical information in one culture can sometimes become difficult to understand in another culture, which needs strength and energy for translation and explanation to make the target language accessible and understandable to the readers and the audience. While there are many cultural factors involved in drama translation with instantaneity of the performance and annotation-free of the dialogue due to the limitation of time and space.

Pinter's works are extremely simple, which can be almost summed up in the so-called minimalist tradition. His works usually present a taste of life with only one room and two or three characters. If one character is enough, Pinter would not allow two. Nor are the plots of Pinter's plays fluctuating. When going to watch Pinter's play, it's not like someone is watching a play, it's more like listening to a play (Deng, 2008). Whenever there is drama, there must be such basic elements as conflict and dramatic action. And according to Aristotle, the best plots are not simple ones, but complex ones. So how did Pinter create his drama in such simple conditions and plots? Language is his greatest weapon. Pinter boldly innovated the traditional theatrical language, combining language authenticity and absurdity as one. On the one hand, his language, unlike traditional dramas, is not filtered by reasoning, but comes directly from life. On the other hand, he is good at capturing the absurdity of real language. Critic Bernard F. Dukore (1982) noticed the dual nature of the Pinteresque language. Pinter's theatrical language is neither Shakespearean harangue of "to live or to die", nor George Bernard Shaw's flowing rhetoric words, but "mostly working-class language with the characteristics of naturalism including vague soliloquies, self-repetition, grammar confusion, incomplete sentences, jumping thought, suddenly changing themes and reluctance to give up the topic that the other side has already given up, like a tape recorder." In fact, these two characteristics are unified: there is the possibility of absurdity in authenticity. The absurd linguistic features that Dukore describes are very close to reality.

Therefore, it is necessary to realize the life-oriented feature of the translation of Pinteresque language under the guidance of reception aesthetics to enable the actors of the target language accurately express the connotation of the drama, quickly convey the emotion of the drama, and enable the target audience smoothly understand the development of the drama story and clearly understand the meaning of the drama.

The Caretaker (Pinter, 1961) was created in 1959, whose subject is typical in Pinter's early works: fighting for a room. There are only three people in the play: two brothers, Aston and Mick, and an outsider, Davies. The conflict in the play revolves around the fight that brought by the outsider who tried to take the place of the caretaker of the room. In his works, Pinter mainly reflects ordinary people, especially those who have no place to live. Therefore, he uses a language that reflects the daily life of the bottom characters in the language presentation.

Original language:

DAVIES All them Greeks had it, Poles, Greeks, Blacks, the lot of them, all them aliens had it. And they had me working there...they had me working... All them Blacks had it, Blacks, Greeks, Poles, the lot of them, that's what, doing me out of a seat, treating me like dirt.

Target langauge: 
戴维斯 那些希腊人都有座位, 波兰人、希腊人、黑人，一大帮子，他们这些外国佬儿都有座位。他们一 直让我在那儿干活......他们一直让我干活.......所有那些黑人都有座位, 黑人、希腊人、波兰人, 他们一大帮子, 这些家伙, 让我连个座位也找不着, 没有把我放在眼里。

This happened when Davies was first invited to Aston's place. Aston invited him to sit, but Davies kept complaining about his previous experience that no one respected him but to ask him to work. All he intended was to earn some respect in front of Aston and strive for a place to live. Davies was a tramp whose language meant to be indecent and foul. So in the target language, it's better to use a language that not that decent, graceful and polite, but vulgar, coarse and rude. So from the expressions “黑人”, “外国佬儿” and “一大帮子”, the Chinese audiences could easily decide that Davies lived at the bottom of the society without too much education. It is because of the real life language that Pinter gave to his character in his plays that the audience can feel the reality of the scene, and thus sense the absurdity behind it. And that is what eco-translation exactly aims to.

In another drama No Man's Land (Pinter, 1975) Pinter used cultural expressions to highlight the elegance of upper class that Chinese audiences might get confused.

Original language:

FOSTER It's a world of eighteenth century cookery books. It's nothing to do with toffee apples and a packet of crisps. It's milk in the bath. It's the cloth bell pull. It's organization.

Target language:

福斯特这里享用的都是法式贵族大餐。从来不吃那些乡巴佬食物。这里用牛奶沐浴, 仆人们都各司其职。 一切都是那么井然有序。

This happened when Spooner and Forster, the servant, began to battle, and both sides began to use the materials they could gather to try to raise themselves up and diminish each other. For the servants Forster and Briggs, their first objective was to highlight their distinguished status, and to exclude Spooner, by a decent life belonging to another class. Therefore, in Forster's words, he used four representative images to express his admiration for the elegant order of the upper class, and used them to flatter his master, show off himself and suppress his opponents. But if literally translated these four images "eighteenth century cookery books", "toffee apples and a packet of crisps", "milk in the bath", and “the cloth bell pull” as “十八世纪的烹饪书”, “太妃苹果和炸薯片”, “浴缸里的牛奶”, “布铃铛绳”, It is more or less difficult for contemporary Chinese audiences in the context of Chinese culture to understand, and is impossible for the Chinese to accurately understand the living standards represented by these images, and may even feel confused at the moment of watching the drama. Therefore, considering translational eco-environment, it is necessary to consider the Chinese audience's general understanding of western culture and use the same or similar imagery to compensate for meaning. So it's necessary to use “法师贵族大餐” and “乡巴佬食物” to compensate for differences in food culture, “仆人们都各司其职” to replace unreadable external cultural symbol, trying to make compensation for the cultural meaning for the life of honor and convey the information intended to be expressed in the drama to the audiences in the context of the target language in a realistic way so that the contextual information in the original language can be easily accepted, which enables the whole process of watching the play to go smoothly and unimpeded, so as for the audiences to get better audio-visual experience.

\section{B. To Realize the Action-directed Feature of the Translation of Pinteresque Language}

The trait of drama itself determines the necessity of using action-packed theatrical language. In a drama, the actors' lines and stage performance together constitute the acting of the drama, and they are supposed to complement each other. That is to say, the stage actions of the actors influence the lines of the characters, and at the same time, the acting of the drama can as well be clearly sensed from the lines of the characters. In the drama, the character language should not only match the external actions of the stage performance, but also display the inner action state of the human being together with the cooperation with the external actions. Especially when there is emotional change of the characters, language will show a strong inner state of action, perfectly combined with external body movements, constitute the whole movement of characters, revealing the characters' state in a specific environment, and thus strengthening the artistic expression of the drama.

If the dramatic translation cannot reproduce the dramatic action language in the source language, the characters created will be descriptive and static and therefore it will be impossible to present the ideas of drama vividly, which makes it difficult for the actors to express their feelings and for the audience to understand the conflict. Under different linguistic and cultural backgrounds, there are obvious differences in the application of language habits, so as to the morphological changes and sentence patterns of spoken English. The purpose of drama translation remains to be performance on stage, which makes it necessary that the target language must be colloquial to enable the actors to easily display the action of language and highlight the dramatic conflicts, and be in line with the linguistic and cultural habits of the target language to enable the audience to better grasp the dynamic nature of the language and understand the development of the plot.

Traditional dramas tend to put social reality before language, that is, to take social reality as the cause, while language as the result, and social reality as the entity, while language as its image. Pinter was aware of the unreliability of language and the danger of communication, he, therefore, boldly changed the one-dimensional cause-result and 
entity-image relationship between social reality and language, and replaced it with the two-way dynamic relationship of mutual causation, which was that social reality determines language to a certain extent, and language can reconstruct social reality as well. The characters in Pinter's plays do the most talking rather than doing something. "In Pinter's play, the most important thing in the verbal communication between characters is what people do to each other rather than what they say to convey in language. (Esslin 1984:90)" For this reason, we cannot understand Pinter's language as a passive carrier of external actions, but language itself becomes a dramatic action. Ignoring this will lead to confusion of understanding. Researchers accustomed to viewing Pinter's works from the perspective of traditional dramatic action will often encounter difficulties, who believes that Pinter's work seems to be a theatrical exercise, not a strict drama. John brown once compared Pinter to a "fan of the car that keeps his car in the garage in excellent condition, but never takes it on a trip. But his is made by hard work, and he is always making new cars." This passage illustrates Pinter's mastery of language, but the idea that the car was intended to travel, apparently derived from Aristotle's theory of imitation, does not apply to Pinter's research.

Over the past four decades, Pinter researchers have gone through two divergent approaches: one is to seek meaning, that is, to take language as a form, focusing on the study of content, for example, the living state and value reflected in the works, that is, the absurdity of life, disillusion, coercion between people, character's subconscious, the symbolic meaning of the work and so on. But the quest for meaning was opposed by Pinter himself. In terms of the creation intention, he has no preset meaning. He opposes the interpreters to attach moral meaning to the work or put the characters into the symbolic framework. Another approach is to study Pinter's language skills, focusing on the stylistic implications and subtexts of the language. However, both approaches ignore the possibility of language as an action, isolating content and form into distinct dualities.

The action of language is the construction or reconstruction of social reality. Language becomes the means by which characters control and dominate others. These characters seldom act, but are keen on the struggle of language, and are deliberately competing in the battle of language in order to gain a favorable position in the relationships in which they are involved. This is best illustrated in a conversation between Forster and Spooner in the play No Man's Land.

Original language:

FOSTER Listen, my friend. This man in this chair, he's a creative man. He's artist. We make life possible for him. We're in a position of trust. Don't try to drive a wedge into a happy household. You understand me? Don't try to make a nonsense out of family life.

Target language:

福斯特 听着, 朋友。椅子上的这个人, 是一个创造者, 是一个艺术家。我们努力照料他的生活, 他很信任 我们，你就甭想着毁坏我们这个幸福的家庭，听明白没？想扰乱我们的家庭生活，没门儿。

It was a battle between Forster the servant and Spooner. Spooner lied on his age and experience to win the sympathy and acceptance of the owner of the house, but it made the servants feel deeply that they wanted to replace them, fearing that their living space in decent homes will be completely taken away. Forster, therefore, was sternly warning Spooner of his deep discontent and anger. He was also very ambivalent at the same time actually, because although still slightly dominant in his identity pride, he has not felt strong enough nor confident enough, but to have to vent his anger and emphasize his close relationship with the host, Hirst, to feel like he can defend his living space. So in translation, word conversion method can be applied. For example, try to use verb phrase “努力照料” that is consistent with Chinese customs to replace “make life possible", use verb “信任” to replace “a position of trust", use the verb “甭” that is morely appeared in spoken Chinese to replace “don't” and use the verb “扰乱” to replace “make a nonsense”, use “没 门儿" to replace "don't", to strengthen the action of language in Chinese context, in order to act out this subtle psychological change, and enable the performance on stage to stimulate the other actors to react appropriately, thus, in turn, to promote the dramatic changes in the plot, and enable the audience to grasp the inner world of the characters quickly and accurately, and deeply understand the plot changes just at that moment.

\section{To Realize the Character-targeted Feature of the Translation of Pinteresque Language}

A good play, a very impressive play, is precisely because there are some vivid characters that leave a deep impression on the audiences. Therefore, one of the important characteristics of drama art creation is the characterization. In novels and other literary forms, the author can achieve his goal by using words to describe the appearance of the characters, the inner activities of the characters and the social background, while in drama, characters' identity, personality, thoughts and feelings are mainly represented by their dialogues. In the stage, actors aim to, through stage behavior and the characteristics of the language, let the audience know the characters' social status, cultural background, understand their heart, go into their inner world, feel the joys and sorrows, and experience characters' image characteristics.

And in the process of drama translation, it's better to start from the perspective of target language audience, and look for language symbols that can reflect the identity and personality of the characters in the target language usage and audience's cultural background, which requires the translator not only to be familiar with the identity background and personality characteristics of the characters and their role in the drama, at the same time, also to have a knowledge of the cultural environment of the target language and the audiences' life experience to determine what kind of language to 
reveal specific images of the characters. Only in this way can the actors effectively master the role of the characters, and enable the audience accurately understand the characters and approach the characters.

Pinter's greatness lies in his ability to bring drama back to its most basic elements. A closed room and unpredictable conversation in which characters can be defeated by each other, and thus all pretensions collapse. A closed space, separated from its material functions, makes it a symbol of human self-identity, which is precisely the absurd irony of Pinter on the predicament of human existence. Pinter's irony is reflected exactly in the characterization of his Pinteresque language which is full of repetitive pauses and blanks, plus a lot of slang. Pinter himself has argued like this: "language is very vague. There is often something unspoken beneath the words spoken. It is in this nature that a language comes into being. I must stress that this language, under the words spoken, has something else to express." So how do we deal with this signifier and signified fracture? Pinter thinks the best solution is silence and pause.

In The Caretaker, the author uses a lot of pauses, as much as one hundred times. When Davies mentioned his identity, his conversation with Aston was full of pauses and hesitations. Similarly, when Aston asked about Davies's birth, Davies hesitated.

Original language:

Davies Well, I been around, you know... what I mean... I been about...

Aston Where were you born then?

Davies (darkly) What do you mean?

Aston Where were you born?

Davies I was... uh...oh, it's a bit hard, like, to set your mind back... see what I mean... going back... a good way... lose a bit of track, like...you know...

Target language:

戴维斯: 我一直到处游荡, 你知道......我的意思是......我一直到处......

阿斯顿: 那么你出生在哪儿?

戴维斯: (脸阴沉沉的)什么意思?

阿斯顿: 你出生在哪儿?

戴维斯: 我......呃......哦......有点难，就像，要回想过去......明白我的意思......回忆 ......很久以前......已经没有 什么记忆了......, 就像....... 你知道......

Davies's pause and hesitancy belied his inner fear of identity, and was meant to distract Aston from his identity. Questioned by Aston, all Davies could do was delay and escape. His true heart and face are seen through pauses in front of the readers and audiences. What Pinter was trying to present in the drama is not that the characters had no ability to communicate, but that, in the play, they often deliberately avoided communication, rather than constantly bickering or talk about other things in order to avoid the sincere communication. In this way, they are safe from the danger of getting to the heart of their relationships.

Drawing from the above, from the perspective of ecological translation, in the process of translation, translators should pay attention to whether the communicative intention in the original text is reflected in the translation, which requires the translator to focus on the adaptability of communication, enable the target language readers and audiences to experience the intentions that the author expressed, and produce resonance or controversy in emotion and thought, which thus achieve the purpose of communication between the author of the original text and the target readers and audiences of the target language.

Therefore, through the Target langauge, Chinese readers and audiences could still feel the confusion of the identity of the tramp Davies. From the beginning to the end, we don't know whether his real name is Davies or Jenkins, because he himself is vague and inconsistent about that. Although he was only a lowly custodian, he never gave up the idea of finding his own identity. Unfortunately, his search for identity was limited to words without action. He repeated the story in endless nagging and complaining. He was a man with a great dream, but now he is just trying to recall the glory of the past to find the destination of his soul. He was helpless in the face of social and personal obstacles and limitations. Despite the dream of returning to the good old days, he had no ability to rebuild the spiritual home, which was a true portrayal of modern western society that Pinter was trying to convey in his original language.

Here is another case in No Man's Land.

Original language:

FOSTER He turns to Briggs.

Why am I bothering? Tell me. Eh?

He turns back to Spooner.

Listen chummy bum.

Target language:

福斯特 (他转向布里格斯。)

我怎么这么恼火呢? 告诉我为什么? 为什么?

他转向斯普纳。)

好一个老乞正, 你给我听着。 
It happened during the first encounter between Spooner and the servants. As Spooner searched for empathy through his own experience and skillfully weaving memories, and step into his inner world becoming more and more accepted by Hirst, Forster lost his temper, being completely enraged, and was very angry. But he had no idea why he became so anxious and angry, and at the same time, being not very high in education degree and class status, he tore through the previous friendly disguise and showed the gray side of his heart directly because of the burning anger. So in translation, it's better to choose to repeat “为什么" twice to increase the frequency aiming to emphasize Forster's anxiety and helplessness. Furthermore, add “好一个” that is very colloquial in Chinese to convey the ironic "chummy" in the original text. In addition, add “老” and “你给我” to highlight Foster's anger and even resentment. Therefore, with these added Chinese grammatical units, actors can better convey the author's writing intention, to directly tear apart Forster's disguise to reveal the character's personality, making it easier for the audience to read into the character's nature when watching the play.

\section{CONCLUSION}

In China, drama is called “话剧”(language drama for its literal meaning), but Pinter's tradition for language is almost the opposite. The language of most traditional drama is fluent and beautiful, but the language of Pinter's play was broken and commonplace with even pauses and silences inserted. He tore up the literary language to be seen, but it was comedy, not tragedy. On the other hand, literary translation requires understanding the basic information and connotation of the original text by carefully studying the original text, grasping the central thought and language features, analyzing specific problems, choosing the most appropriate translation strategy for the overall framework, and applying the most appropriate translation skills for specific implementation. In addition, each type of literary texts, because of influential factors like different range, different approach and different times of acceptance, will inevitably make it different as for the purpose achieved through translation. Therefore, when translating Pinter's plays, the translation ecological environment should be considered with the knowledge of achieving literary readability, stage performability and performance appreciability of Pinter's plays. It's also necessary to comprehensively collect the relevant information of the original text, understand the author's background and other related work, study the content of the works and various meanings, analyze the target language audiences and evaluate the target language cultural environment to finally work out what the audience can get from the translation, what needs to be learned from the drama watching process, and how can they better accept what needs to be accepted. With all these in mind, the translator looks for the best channel to build the most suitable bridge between the audiences and the work, so as to realize the best connection between the two.

From all the above, it's only when guided by the ecological translation theory and applying the most appropriate translation strategies and techniques with flexible and principled analysis and processing of the original text to realize the life-oriented, action-directed and character-targeted features of the translation of Pinteresque language that the translation of Pinter's play could achieve literary readability, stage performability and performance appreciability to better construct the audiences' acceptance space and meet the audiences' expectations. Thus, actors and audiences in the Chinese language context could easily accept and understand the plot of the drama and the author's intention, so that more audiences in the Chinese mainland can enjoy and fully appreciate the beauty of Pinter's outstanding drama.

\section{REFERENCES}

[1] Brown John Russel. (1984). “Action and Control: The Homecoming\& Other Plays by Harold Pinter”. Modern British Dramatists. Englewood Cliffs. NJ: Prentice Hall, Inc.

[2] Esslin Martin. (1970). The Peopled Wound. NY: Doubleday Anchor Books.

[3] Deng Di. (2008). The Audience-oriented Translation Strategy. Shanghai Theatre, 4, 32-34.

[4] DukoureF. Bernald. (1982). Harold Pinter. London: MacMillan Education.

[5] Fang Bolin. (1996). Harold Pinter's Language Play. Shangdong Foreign Languages Journal, 4, 38-41.

[6] Hu Gengshen. (2008). Eco-translatology: A Primer. Chinese Translators Journal, 6, 11-15.

[7] Pinter Haorld. (1961). The Caretaker The Dumb Waiter: Two Plays by Harold Pinter. NY: Grove Press.

[8] Pnter Harold. (1975). No Man's Land . London: Eyre Methuen.

[9] Prentice Penelope. (1991). Harold Pinter: Life, Work, and Criticism. New Brunswick: York Press.

[10] Silverstein, Marc. (1993). Harold Pinter and the Language of Cultural Power. London and Toronto: Associated University Presses.

[11] Skyes Altrene. (1970). Harold Pinter. New York: Humanities Press.

[12] Taylor John Russell. (1969). Harold Pinter. London: Longmans Green.

Sainan Li was born in Hebei, China in 1984. She received her MA Degree in School of Foreign Language from Yangzhou University, China in 2012.

She is currently a teacher of Faculty of Foreign Languages of Huaiyin institute of Technology, Jiangsu, China. She majors in Linguistics and English Literature. 
Zi Li was born in Jiangsu China in 1982. She has received her MA Degree in PLA University of Foreign Language majoring in Translation in 2011.

She is currently a teacher of Faculty of Foreign Languages of Huaiyin institute of Technology, Jiangsu, China. 